\title{
Study on the Spatial Morphological Characteristics of Traditional Village Settlements in Nanxijiang River Basin
}

\author{
Yixi Liu ${ }^{1,2}$ Zhiyao $\mathrm{Ma}^{1, *}$
}

\author{
${ }^{1}$ School of Architecture, Tianjin University, Tianjin 300072, China \\ ${ }^{2}$ Department of Art and Design, Zhejiang Tongji Vocational College of Science and Technology, Hangzhou, Zhejiang \\ 311231, China \\ *Corresponding author. Email: mazhiyao1971@163.com
}

\begin{abstract}
Traditional villages contain a long history of the nation, which is an important carrier for reviving traditional culture and an important link in the implementation of rural revitalization strategies. The field survey method is used to investigate the representative Yanlong Village in the Nanxijiang River Basin to analyze the layout and internal attributes of the building space. The study found that the overall layout of Yanlong Village contains an ideal geomantic residential mode. The main architectural forms are mainly beam-lifting and column and tie wooden frames. The architecture is harmonious with yin and yang, and has the typical essence of farming-reading culture, reflecting the regional and cultural characteristics of the architectural form of the Nanxijiang River Basin. And at last, some protection strategies are proposed.
\end{abstract}

\section{Keywords: Nanxijiang River, traditional village, settlement space, Yanlong Village}

\section{INTRODUCTION}

In the 19th National Congress of the Communist Party of China, a strategy for rural revitalization was proposed, with the goal of "prosperous industries, ecological livability, rural civilization, effective governance and a wealthy life", to promote the revitalization of rural industries, ecology, culture, talents, and organizations. Traditional villages have a long history of the nation and are an important carrier for reviving traditional culture. They are also one of the five major revitalization of the countryside. Rural culture is an important cultural cornerstone of rural grass-roots governance and modernization. Without the self-confidence of rural culture, it is difficult to achieve the revitalization of rural culture. General Secretary Xi Jinping also made an important exposition on rural culture: "We need to dig deeper, inherit and innovate excellent traditional local culture." Its essence is to "activate" the local cultural atmosphere contained in traditional villages, so as to realize the innovation and development of cultural heritage and intangible cultural heritage in the inheritance and reproduce its cultural charm and style. Cultural heritage should revolve around traditional villages. First of all, the living

*Fund: Supported by the Youth Fund for Humanities and Social Sciences Research of the Ministry of Education (19YJC850005); Zhejiang Science and Technology Association Talent Training Project (2018YCGC020). environment and traditional cultural context are inseparable [1]. On the one hand, the built environment is a material carrier of intangible culture [2], and meanwhile, culture also affects the built environment. The two are interrelated. On the other hand, architectural cultural landscapes have significant landscape genes [3], and social foundation and cultural heritage are their internal and external motivations. Secondly, in terms of the continuity of cultural heritage, related scholars discussed the core points of the protection of intangible cultural heritage [4], the morphological space cultural characteristics and protection of traditional villages [5], and the path selection of rural cultural revitalization [6]. Its core lies in innovative protection, rather than traditional conservative ideas. Finally, the existing technology and economic foundation guarantee the sustainability of traditional culture. The cultural connotation resides in people's living environment. The protection of environmental space must rely on economic and technological guarantees [7]. Based on this, promoting and inheriting excellent traditional culture based on cultural self-confidence is the only way to promote the revitalization of rural culture, and it is also a valuable asset for the sustainable development of traditional villages, which is worthy of in-depth discussion and research. The most important part of the living environment is the traditional residential buildings in the traditional villages. Its internal structure and 
decoration not only inherit the traditional building construction technology, but also represent a typical example of regional culture.

The traditional villages in the Nanxijiang River Basin of Yongjia County, Wenzhou City, Zhejiang Province are the complete pedigree of Chinese agricultural settlements [8], which are called national treasures by Professor Chen Zhihua of Tsinghua University, and are worthy of in-depth research and discussion. Yanlong traditional village is located in the north of Yongjia County, Wenzhou City, Zhejiang Province, and upstream of the Nanxijiang River Basin. It has superior natural and cultural resources. It is the fifth batch of national-level traditional villages, Chinese landscape villages, and famous historical and cultural villages in the province. Yanlong Village was built during the Chunyou period of the Southern Song Dynasty (1241-1252). According to "Genealogical Prologue of Yanchuan Ji's Family" in the 5th year of Wanli in Ming Dynasty, wrote by Zhang Shiyang, who was a student in Nanjing Imperial College and was the Sima of Dongcheng Troops, "Ji's family in Yanliao was a huge tribe in Yongjia. Their ancestors lived in Longquan, Chuzhou. During the Jianyan period of the Southern Song Dynasty, Ji Ling, an assistant minister of the Ministry of Revenue in feudal China, moved his family to Wenzhou after being appointed a feudal provincial in Wenzhou. During Chunyou's reign, Ji Duo, Sangong of the Yuan Dynasty, repeatedly admonished Song Lizong of Song Dynasty, but Lizong didn't listen. And Ji Duo then took a leisurely tour of the mountains and rivers to the place of Yanchuan in Qingtong Township." Ji's family has been living in Yanlong Village for nearly 800 years so far.

\section{GENERAL SITUATION OF THE VILLAGE}

Ji's family in Yanliao was a huge tribe in Yongjia. Yanlong Village is a blood-based settlement village mainly based on the surname of Ji. During the Chunyou period, Ji Duo (surnamed "Sizhen"), Sangong of Jiling, traveled to Yanlong due to unsuccessful official careers, and moved here, becoming the ancestor of Ji's family in Yanlong [9]. In the Xianchun region, Southern Song Dynasty, the descendant Ji Yu (surnamed Mengdao), served as assistant minister and prefecture chief of Yangzhou. The layout of Yanlong Village contains the concepts of yin and yang, the five elements and the geomantic construction concept, which reflects the living ideal of the ancestor of the Ji family. The village plan is in neat formation, the layout is wellproportioned, the village plane is shuttle-shaped with obvious characteristics of the geomantic site selection concept, as shown in "Fig. 1". The overall architecture of the village faces southwest, and is stepped upward and arranged in layers. To the north is Zhaijian Mountain, where the grave mound is located. There is the tomb of the ancestor $\mathrm{Ji} \mathrm{Yu}$, located on the water level. The south relies on Longtou Paoshan, which looks like a pen holder. The two cliffs face each other and the space is narrow and long. The southeast exit is the village's water mouth, with stone arch bridges and Guansheng Temple. There is a pit in the middle of the stream that runs through the entire village. The road along the brook (Yanlong Middle Road) is the main trunk road of the village. The internal road is three vertically and two horizontally arranged, and the village ancestral hall and residential buildings are wellproportioned laid out. Among them, the Ji's Ancestral Hall was built during the Jianyan period of the Southern Song Dynasty, facing north. In front of the ancestral temple, there are millennial camphor trees against the background. Surrounded by terraces, it belongs to a typical idyllic landscape environment. The gate located in the village is a pool of water that gathers and hides in the village. Guansheng Temple calm surroundings, which can be described as sheltering from wind and water, forming an ideal geomantic residential mode of "pillowing mountains, surrounding water, and face screen". At the same time, Yanlong Village is one of the traditional villages with relatively complete preservation in the Nanxijiang River Basin. It retains a large number of Ming, Qing and Republican buildings. Among them, there were 18 cultural relics before the Qing Dynasty and many ancient tree resources were preserved. Among them, there are 4 first-class ancient trees.

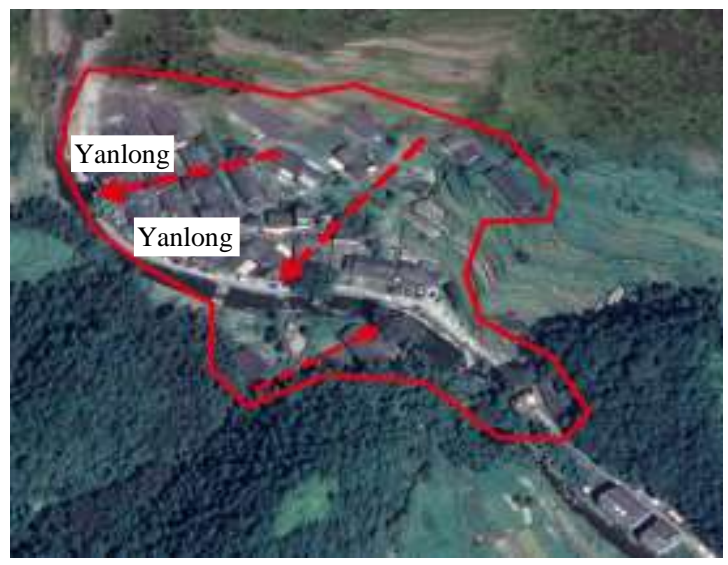

Fig. 1. Layout of Yanlong Village.

\section{SPATIAL FORM OF VILLAGE BUILDINGS}

\section{A. Spatial form of clusters}

Yanlong Village, as a typical mountain village in the Nanxijiang River Basin, forms a continuous and different-oriented residential cluster, which is different from the uniformly-oriented residential clusters formed by the plain villages in the Nanxijiang River Basin [10] The form of residential clusters is between the "individual" and "entirety" of the building. It tends to evolve in the overall form of the village and develops 
along the stream in sequence, forming three typical types of residential clusters $\mathrm{A}, \mathrm{B}$, and $\mathrm{C}$, as shown in the "Fig. 2". First, the A-type residential clusters are located on the northwest side of Yanlong Village. The individual residential units face southwest and are built facing the stream. The number is large, the volume is large, it is well-proportioned, and the azimuth is about $240^{\circ}$. Secondly, the B-type residential clusters are located on the southeast side of Yanlong Ancient Village, with a small number. They are built near the mountain and face the stream. The individual residential units sit on the southwest and face northeast, with an azimuth of about $53^{\circ}$. Third, the C-type mixed scattered pattern clusters: located on the north side of Yanlong Ancient Village in a scattered layout, mostly facing southwest and facing the stream, but the Ji's Ancestral Hall is a building facing south and has a more square shape, locating in the center of the building complex and reflecting its core position.

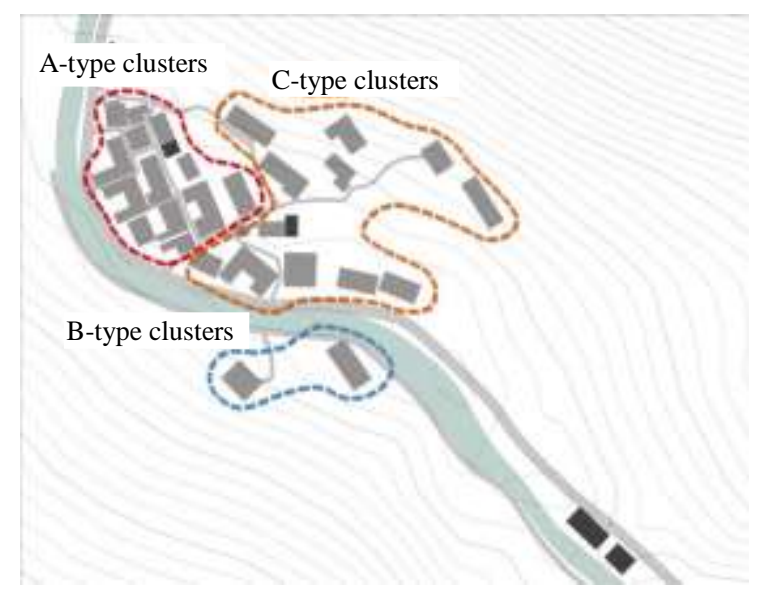

Fig. 2. Distribution of residents clusters in Yanlong Ancient Village.

\section{B. Individual space form}

The residential buildings in the village are limited by the topography, and are arranged in a platform-type vertical depth. The flat buildings are in the shape of "", "L", and "凹". The two floors of the building are mostly, and the housing is basically one-stage. The base of the building is about $0.33 \mathrm{~m}$ (one foot) above the ground, and combined with low walls to form a courtyard space. There are various forms of residential buildings in the village. First of all, the "-"-shaped buildings: The number of such buildings is the largest, $80 \%$ of the central rooms are open halls, with large living spaces, and the Shaojian (rooms at both ends of the building) and Jinjian (room on the outermost side of the building) are prominent. Its utility room, livestock barn, poultry house, etc. are located on the side of main building. Second, the "L"-shaped buildings: This type of building is based on the "-"-shaped building, with right-angled sides plus one to five rooms at the sides and ends, forming an architectural form with different lengths on both sides. There is a "lane" between the wing rooms and the main room, which is connected to the front eaves space of the hall, enhancing the building's ventilation and lighting. Alleys and kitchens (usually located at the end of the main room) are connected to the external long steps to facilitate residents' access. Finally, the " " "-shaped buildings: This type of building is generally symmetrical about the central axis to bring life together. It also varies due to different living space requirements. On the basis of the "-"-shaped building, the right and left sides of the two sides are added with two to five rooms with rightangled, and stone walls are built to form the courtyard space.

\section{VILLAGE ARCHITECTURAL FEATURES AND STYLES}

The architecture of the traditional village of Yanlong has a long history, which can be traced back to the Song Dynasty. The entire village has about 26 houses, 18 of which were built before the Qing Dynasty. The residential houses in the village are mostly in the shape of "-", mainly satisfying the residential functions, and there are a small number of Sanheyuan-style building forms. The building is dominated by wooden structures, usually two floors, and the height is generally 8 meters. It used beamlifting and column and tie wooden frames type. The platform foundation is generally about 0.33 meters above the ground, and generally, there are about $1.3 \mathrm{~m}$ walls surrounding the house and ancient trees. Among them, some homes choose to use 5 and 9 as the number of open rooms. In positive numbers, the number 9 is the highest, and the number 5 is in the midst. "9" and "5" symbolize power. There is a saying in "the Book of Changes": "The heaven itself can change to form everything in the universe, and all things have real life because of heaven. Therefore, if everything can maintain its original state of giving life and harmony, then it is truly a great and chaste life". In "Doctrine of the Mean", it also mentioned that, "Moderation is the most fundamental of the world, and "harmony" is the law followed by the world. When moderation and harmony are reached, the heavens and the earth will rest in their place, and everything will grow and develop". This saying also contains such meaning. In architecture, not only geomancy is pursued, but also the unity of heaven and man is yearned for. In addition, the farming-reading culture of the Nanxijiang River Basin also deeply affects the architectural form of the village. The orientation, location, room and details of the internal structure are also rich in the characteristics of the ancient Nanxijiang River, which contains the essence of the Nanxijiang River's indigenous architectural culture. 


\section{A. Ancestral hall buildings}

Ji's Ancestral Hall, the seventh national key cultural relics protection unit, was built during the Lizong region of Song Dynasty. It was built because Ji Ling saved the prince with has credit. After it was destroyed in the 14th year of Zhengtong period in Ming Dynasty, it was rebuilt on the original site by its descendants. The ancestral hall occupies an area of about $485 \mathrm{~m}^{2}$ and is $6 \mathrm{~m}$ high. It has an entrance hall, a central hall, a corridor, and a dormitory to form a " 回 "-typed quadrangle dwellings. There are stone lions and memorial gates at the door. The entrance hall is divided into five rooms, and the corridors on both sides are each divided into four rooms. The central hall (theatrical stage) is the main building. It has two corridors with surrounding corridors, a gable and hip roof, an invertedpot at the bottom, a drum-shaped column foundation, supported by four circular wooden columns, and the side angles are obvious. Half-moon-shaped dragon whiskers are engraved on both ends of the beam, and they are supported by a header arch and a fan-shaped bird with a "万" pattern. They are often used in typical architectural forms of ancestral halls. The main hall of the dormitory is divided into three rooms, five meters long, with a quadruple-entry side room on each side. The roof is suspended from the top of the mountain, covered with small green tiles, and the wings are turnup. The beam frame adopts a beam-lifting structure to form the space skeleton of a triangular double-slope roof house. The house supports the overall space through rafters, purlin, beams, columns, etc., which is beautiful, secure and practical [11], and meets the clearance requirements of the ancestral hall.

In short, the "回"-shaped architectural form of the Ji's Ancestral Hall has a large volume and exquisite interior decoration. It is the core building in the entire village. It almost considers the hall as the core key to the destiny of the clan. This is closely related to the concept of "respecting the ancestor and living harmony with the clan" in the feudal patriarchal system characterized by the ancestral clan rights after the Song and Ming Dynasties. It also reflects the position of the ancestral hall in the village, and it also contains the beautiful vision of the ancient family's prosperity and talented descendants. At the same time, the Ji's Ancestral Hall has high requirements on construction technology and a large amount of construction projects. It still needs to be built on imperial orders in order to solve economic and technological problems. Of course, the "回"-shaped buildings are gathered together, which is in line with the characteristics of the consanguinity settlement village. The buildings should not only be majestic and magnificent, make people awe-inspiring, but also strengthen the clan cohesion and management of clan power. Its cluster discussion is an important organizational form of the ancient Chinese rural governance system.

\section{B. Residential buildings}

Ji Tongyi residential buildings, typical Qing-style buildings, are the first batch of Yongjia historical buildings. The residential buildings are different from other building groups. They are located on the shaded side, facing northeast. The layout is parallel to the stream, facing the stream, the terrain is about $0.6 \mathrm{~m}$ higher than the road surface, and there are about $1.2 \mathrm{~m}$ surrounding walls, which enclose a relatively closed and independent space. In front of the door are two ancient sweet gum trees, which play a role in landscaping and blocking the visual field, highlighting the original owner's feelings of living alone. The residential building is a building layout of two floors and nine rooms. In ancient China, the odd numbered rooms were positioned as "yang" (positive). In yang numbers, the number 9 is the highest, and the number 5 is in the midst. "9" and "5" symbolize power. This is from the saying in "the Book of Changes": " The heaven itself can change to form everything in the universe, and all things have real life because of heaven. Therefore, if everything can maintain its original state of giving life and harmony, then it is truly a great and chaste life". The residential building adopts the "five-purlin, five-pillar and two-tied" construction rule of a column and tie type wooden frame [12]. The columns are connected in series by a through-pile, and the purlins are set on the column heads. In this way, a triangular house supporting structure staggered and arranged in an orderly manner is formed, and the wall can be installed in the form of siding or mud wall. In terms of construction dimensions, the diameter of the column is about $0.25 \mathrm{~m}$, the cross section of the through-pile is about $5 \times 15 \mathrm{~cm}^{2}$, the purlin distance is generally between 0.4 to $2 \mathrm{~m}$, the materials of rafter are generally about $3 \times 5 \mathrm{~cm}^{2}$, and the tiles are directly laid on the rafter without any roof boarding or shedthins tile. This method has the characteristics of low cost of materials, process requirements, labor costs, etc. It is especially suitable for housing construction in mountainous areas, where materials can be drawn on local resources, which is convenient for large-scale popularization and application. This structural form is more common in the traditional villages of Nanxijiang River, and it is also one of the forms of more residential houses adopted in the Ming and Qing Dynasties.

Therefore, from the perspective of the building as a whole, the first is to show the characteristics of "yin" in terms of layout, but the number of rooms is "yang". The harmony of yin and yang in the building reflects the perfect combination of etiquette, order and beauty. The second is that its internal structure is designed and built with a column and tie ancient architecture, which is integrated with the natural and ecological environment 
of the Nanxijiang River Basin. Third, the building is based on local materials and integrates well with the ecological environment. It considers a more comfortable living space, and the overall courtyard is relatively independent. It forms a closed life circle and reflects the meaning of seclusion.

\section{CONCLUSION}

The architectural space form and construction method of traditional villages are the result of multiple choices with ecological environment, farming culture, economic technology, and lifestyle. When this lifestyle and architectural form is widely recognized and constructed in large numbers, it gradually forms a architectural paradigm [13]. The basic form of the settlement of the traditional dwellings in the mountains of Yanlong Village is also formed in the long-term development based on the natural, economic, and social interaction under the choice of the paradigm. It has typical characteristics of the times. Of course, influenced by the essence of the farming-reading culture of Nanxijiang River, in the location and spatial layout of the spatial form layout, Ji's ancestor's habitation ideal of "unity of heaven and man" was also accumulated. At the same time, the traditional residential settlements in traditional villages adapt to the natural environment of the region, and gradually evolve in the form of architectural space according to the differences in living and functional needs, which are reflected in the characteristics and style of the buildings. The step-by-step improvement process of "single — function — courtyard" makes the architectural space present a stable and similar architectural space form, and it is also an innovative paradigm of cultural heritage. Therefore, in the protection and use of traditional villages, it is necessary to not only respect the paradigm of the characteristics of its architecture, but also consider the inheritability of the cultural carrier of its architectural form. Only promoting and inheriting excellent traditional culture based on cultural self-confidence is the only way to promote the revitalization of rural culture.

Of course, the construction skills of Yanlong Village are the continuation and innovation of the Song Dynasty's "Constructing Methods" and the "Engineering Practices" and other rules. Its architectural houses and cultural connotations are still intact. It has certain historical, artistic, and cultural values in terms of construction technology and decorative arts, which is worthy of deep excavation and cultural revitalization. Therefore, traditional villages are an important carrier for reviving traditional culture. In the protection and utilization of traditional villages, it is necessary to seize their cultural connotations and innovate protection theories. The key to the rural revitalization strategy is to respect the historical precious resources and treasure, and to grasp the soul of traditional village culture, so as to make the culture "alive", increase its value, and gain the impetus of endogenous protection.

\section{References}

[1] Yang Dinghai. Study on Traditional Settlement and Architectural Space Form of Hainan Island [D]. South China University of Technology, 2013. (in Chinese)

[2] Xiong Ying. Study on Rural Built Environment Based on Meishan's Intangible Cultural Heritage [D]. Hunan University, 2014. (in Chinese)

[3] Zhang Haolong, Jin Wanfu, Zhou Chunshan. Architectural Cultural Landscape Characteristics and Formation Mechanism of Zhaoqing Traditional Villages [J] .Tropical Geography, 2017,37 (03): 304-317. (in Chinese)

[4] Ma Zhiyao, Liu Zhiying, Liu Yaoyao. Several Key Issues of the Concept of Protection of China's Intangible Cultural Heritage [J]. Folklore Research, 2019 (6): 39-46. (in Chinese)

[5] Liu Yixi, Hu Chun, Ma Zhiyao. Morphological Characteristics of Traditional Village Settlements in the Nanxijiang River Basin: A Case Study of Yubei Village [J]. Interior Design and Decoration, 2019 (12): 124-125. (in Chinese)

[6] Long Wenjun, Zhang Ying, Wang Jiaxing. The Realistic Explanation and Path Choice of Rural Culture Revitalization [J]. Agricultural Economic Issues, 2019 (12): 15-20. (in Chinese)

[7] Liu Yixi, Wang Ning, Wang Yana, et al. Research on Traditional Village Protection and Inheritance Optimization Strategies Based on Spatial Syntax: Taking Yongjia Furong Village as an Example [J]. Journal of Tianjin University (Social Science Edition), 2020, (3). (in Chinese)

[8] Chen Zhihua, Li Qiuxiang. Rural China: Ancient Villages in the Middle Reaches of Nanxijiang River [M]. Shanghai: SDX Joint Publishing Company, 2005. (in Chinese)

[9] The Office of the Third National Cultural Relics Census Leading Group of Wenzhou. Wenzhou Ancient Villages [M] Hangzhou: Zhejiang Ancient Books Publishing House, 2017.05 (in Chinese)

[10] Lin Moyang, Liu Yixi. Morphological Types and Characteristics of Traditional Villages in Nanxijiang River Basin, Yongjia County $[\mathrm{J}]$. Journal of Wenzhou Vocational College of Science and Technology, 2018,1 (1): 11-16. (in Chinese)

[11] Xu Han. Chinese Art Encyclopedia, Graphic Collector's Edition, Vol.4, Architecture Art [M]. Beijing: People's Publishing House, 2006.06. (in Chinese)

[12] Zhao Xinliang. Poetic Habitat: A Cultural Interpretation of Traditional Chinese Houses (Vol. 2) [M]. Beijing: China Construction Industry Press, 2009.08 (in Chinese)

[13] Wang Dong. Technical Paradigm of Rural Architecture and Its Transformation [J]. Journal of Architecture, 2003 (12): 23-25. (in Chinese) 